\title{
Risk factors for seromucinous benign ovarian cysts in northern Italy
}

\author{
Fabio Parazzini, Simona Moroni, Eva Negri, Carlo La Vecchia, Raffaella Mezzopane, \\ Pier Giorgio Crosignani
}

\begin{abstract}
Study objective-To analyse risk factors for seromucinous benign ovarian cysts. Design-Between 1984 and 1994 a casecontrol study was carried out. Cases were 225 women aged less than 65 years with a histologically confirmed diagnosis of benign seromucinous ovarian cysts admitted to a network of obstetrics and gynaecology departments in Milan. Controls were a random sample of 450 women admitted for acute conditions that were not gynaecological, hormonal, or neoplastic. They were interviewed within the framework of a case-control study of female genital neo-
\end{abstract} plasms.

Setting-Network of hospitals in the greater Milan area, Italy.

Main results-The risk of seromucinous benign ovarian cysts was higher in more educated women than in women with fewer than seven years of schooling. The odds ratios (OR) for seromucinous ovarian cysts were 1.3 and 1.4 respectively in women reporting $7-11$ and $\geq 12$ years of schooling, and the trend in risk was statistically significant $\left(\chi^{2}\right.$, trend $\left.5.20, p<0.05\right)$. There was no clear relationship between the risk of seromucinous ovarian cysts and marital status, age at first marriage, oral contraceptive use, smoking, or body mass index. In comparison with women reporting menstrual cycles lasting $<28$ days, the risks of seromucinous cysts were 1.6, 2.6 , and 2.5 respectively in women reporting cycles lasting $28-30, \geq 31$ days, or with totally irregular ones. Among ever married women, nine cases and two controls reported difficulty in conception, and the corresponding $O R$ for seromucinous cysts was 17.7 (95\% confidence interval 4.2, 83.8).

Conclusions-The risk of seromucinous benign ovarian tumours is greater in more educated women and in women with a history of infertility and with long or irregular menstrual cycles.

( 7 Epidemiol Community Health 1996;51:449-452)

Ginecologica, Istituto

Nazionale Tumori,

Milan, Italy

S Moroni

Istituto di Statistica Medica e Biometria, Università degli Studi di Milano,

Milan, Italy

C La Vecchia

Correspondence to: Dr F Parazzini.

Accepted for publication October 1996 suggests that benign and malignant lesions may share similar aetiological profiles. Clinical observations and epidemiological studies have suggested that benign ovarian cysts are more common in nulliparae and in women reporting a history of infertility, but the findings are scanty and controversial. ${ }^{2-4}$ Furthermore, most of these studies did not separately analyse different histological subgroups of benign ovarian cysts, including endometrioid and seromucinous benign ovarian lesions, ${ }^{24}$ which are two different conditions. To offer further data on the epidemiology of benign seromucinous ovarian cysts, we present the results of a casecontrol study conducted in northern Italy within the framework of a larger study on risk factors for benign and malignant ovarian diseases. $^{35}$

\section{Methods}

Between 1984 and 1994 we conducted a casecontrol study of benign ovarian cysts. ${ }^{3}$ Cases were women aged less than 65 years with a histologically confirmed diagnosis of benign seromucinous ovarian neoplasm, admitted to a network of obstetrics and gynecology departments in Milan. A total of 225 women with an age range between 15 and 64 years (median age 38 years) was interviewed.

Potential controls were women below the age of 65 years admitted for acute non-gynaecological, non-hormonal, non-neoplastic conditions to the Ospedale Maggiore (including the four major teaching and general hospitals in Milan) and several specialist university clinics, serving a catchment area similar to that of the hospitals where cases had been identified. They were recruited within the framework of a casecontrol study of female genital neoplasms. Out of a total of 2654 subjects interviewed, 450 controls were identified (age range 16-64 years; median age 38 years), matched with cases in a $1: 2$ ratio, and randomly selected within strata of five year age groups and calendar years of interview. Of these, $34.4 \%$ were admitted for traumatic conditions (mostly fractures and sprains), $25.8 \%$ had non-traumatic orthopedic disorders (mostly low back pain and disc disorders), $16.7 \%$ acute abdominal diseases requiring surgery, and $23.1 \%$ other miscellaneous illnesses, such as disorders of the ear, nose, throat, or teeth.

Trained interviewers identified and questioned cases and controls. All interviews were conducted in hospital. Less than $3 \%$ of cases and controls refused to be interviewed. Information was obtained, using a structured 
Table 1 Distribution of 225* cases of seromucinous benign ovarian cysts and 450 controls and corresponding odds ratios, according to age and selected characteristics. Milan, Italy, 1984-94

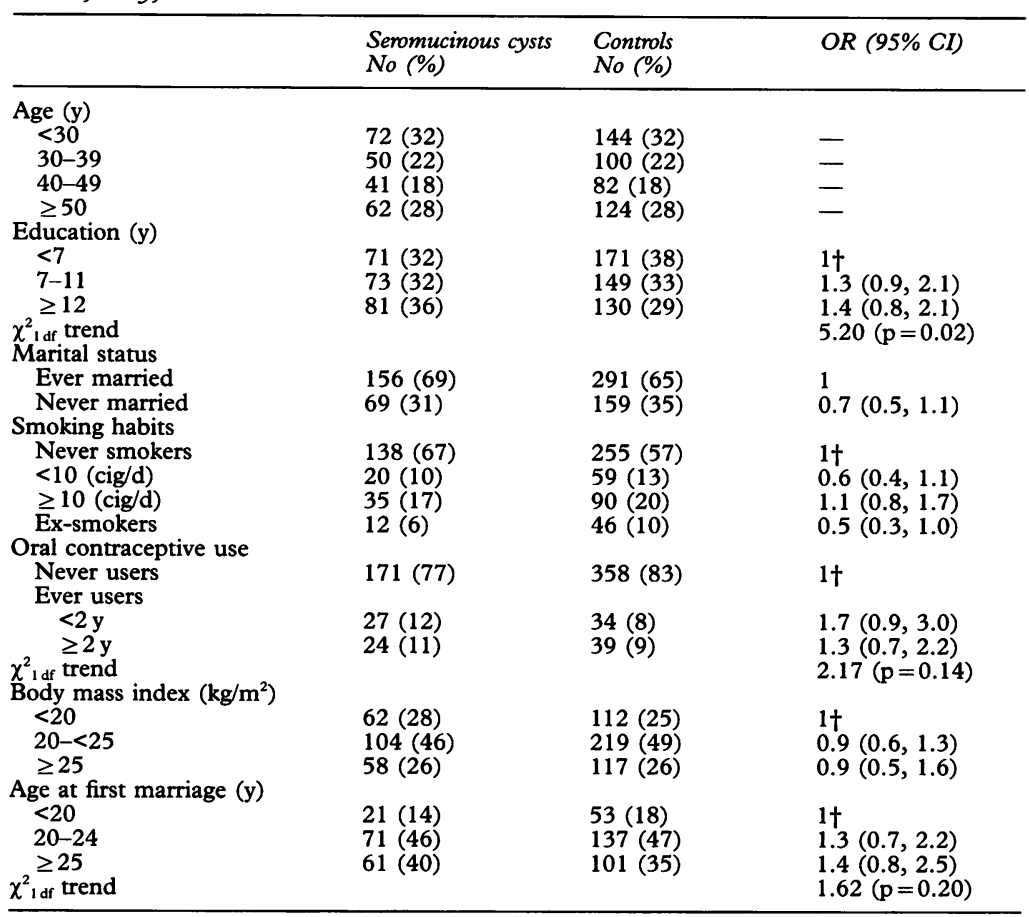

* In some cases the sum does not add up to the total because of missing values.

† Reference category; OR=odds ratios adjusted for age; $\mathrm{CI}=$ confidence intervals. $\mathrm{df}=$ degree of freedom.

¥Ex-smokers excluded.

Table 2 Distribution of $225^{*}$ cases of seromucinous benign ovarian cysts and 450 controls, and corresponding odds ratios, according to menstrual and reproductive factors. Milan, Italy, 1984-94

\begin{tabular}{|c|c|c|c|}
\hline Characteristics & $\begin{array}{l}\text { Seromucinous cysts } \\
\text { No }(\%)\end{array}$ & $\begin{array}{l}\text { Controls } \\
\text { No (\%) }\end{array}$ & OR $(95 \% C I)$ \\
\hline $\begin{array}{l}\text { Age at menarche }(y) \\
\geq 11 \\
12-13 \\
\geq 15 \\
\chi_{1 \text { df }}^{2} \text { trend } \\
\text { Age at menopause }(y)\end{array}$ & $\begin{array}{l}44(20) \\
118(53) \\
62(28)\end{array}$ & $\begin{array}{l}101(23) \\
204(46) \\
144(32)\end{array}$ & $\begin{array}{l}1 \dagger \\
1.3(0.9,2.2) \\
1.0(0.6,1.6) \\
0.07(p=0.79)\end{array}$ \\
\hline $\begin{array}{l}\text { Pre/perimenopausal } \\
<50 \\
\geq 50\end{array}$ & $\begin{array}{l}168(75) \\
24(11) \\
33(15)\end{array}$ & $\begin{array}{l}330(74) \\
64(14) \\
50(11)\end{array}$ & $\begin{array}{l}1 \dagger \\
0.7(0.4,1.2) \\
1.1(0.7,1.9)\end{array}$ \\
\hline $\begin{array}{l}\text { Lifelong menstrual pattern }(\text { d) } \\
<28 \\
28-30 \\
\geq 31 \\
\text { Totally irregular }\end{array}$ & $\begin{array}{l}21(10) \\
151(69) \\
23(11) \\
23(11)\end{array}$ & $\begin{array}{l}82(19) \\
275(62) \\
42(10) \\
44(10)\end{array}$ & $\begin{array}{l}1 \dagger \\
1.6(0.9,2.7) \\
2.6(1.2,5.8) \\
2.5(1.1,5.6)\end{array}$ \\
\hline $\begin{array}{l}\text { Parity } \\
0 \\
1 \\
\geq 2\end{array}$ & $\begin{array}{l}103(46) \\
44(20) \\
77(34)\end{array}$ & $\begin{array}{l}195(43) \\
89(20) \\
166(37)\end{array}$ & $\begin{array}{l}1 \dagger \\
1.0(0.6,1.6) \\
0.9(0.5,1.4)\end{array}$ \\
\hline $\begin{array}{l}\text { Age at first birth (y) } \\
<25 \\
\geq 25\end{array}$ & $\begin{array}{l}50(41) \\
71(59)\end{array}$ & $\begin{array}{l}134(53) \\
120(47)\end{array}$ & $\begin{array}{l}1 \dagger \\
1.3(0.7,2.2)\end{array}$ \\
\hline $\begin{array}{l}\text { Age at last birth }(y) \\
<25 \\
25-29 \\
\geq 30 \\
\chi_{1 \text { df }}^{2} \text { trend }\end{array}$ & $\begin{array}{l}19(16) \\
42(35) \\
60(50)\end{array}$ & $\begin{array}{l}54(21) \\
101(40) \\
99(39)\end{array}$ & $\begin{array}{l}1 \dagger \\
1.3(0.5,2.0) \\
1.5(0.8,2.8) \\
1.99(p=0.16)\end{array}$ \\
\hline $\begin{array}{l}\text { Spontaneous abortions } \\
0 \\
\geq 1 \\
\text { Induced abortions }\end{array}$ & $\begin{array}{l}191(85) \\
34(15)\end{array}$ & $\begin{array}{l}387(86) \\
63(14)\end{array}$ & $\begin{array}{l}1 \dagger \\
1.1(0.7,1.7)\end{array}$ \\
\hline$\stackrel{0}{\geq 1}$ Difficulties in conception $\neq$ & $\begin{array}{l}202(90) \\
23(10)\end{array}$ & $\begin{array}{l}405(90) \\
45(10)\end{array}$ & $\begin{array}{l}1 \dagger \\
1.1(0.6,1.8)\end{array}$ \\
\hline $\begin{array}{l}\text { Never } \\
\text { Ever }\end{array}$ & $\begin{array}{l}147(94) \\
9(6)\end{array}$ & $\begin{array}{l}289(99) \\
2(1)\end{array}$ & $\begin{array}{l}1 \dagger \\
17.7(4.2,83.8)\end{array}$ \\
\hline
\end{tabular}

* In some cases the sum does not add up to the total because of missing values.

$\dagger$ Reference category; $\mathrm{OR}=$ odds ratios adjusted for age; $\mathrm{CI}=$ confidence interval, $\mathrm{df}=$ degree of freedom

$\ddagger$ Married women only.
Women were defined as post-menopausal if their last menstrual period had occurred more $c$ than one year before the interview. History of $\frac{m}{0}$ infertility was defined as two or more years of unsuccessful attempts at pregnancy.

DATA ANALYSIS

Odds ratios (OR), as estimators of relative risks of benign seromucinous ovarian cysts, together with their $95 \%$ approximate confidence intervals (CI), were computed from data stratified for age by the Mantel-Haenszel $\stackrel{\vec{F}}{\vec{F}}$ procedure. ${ }^{6}$ Further allowance for calendar years at interview in quinquennia did not change the estimates, thus only age adjusted ones are presented. When a factor could be classified into more than two ordered levels, the significance of the linear trend was assessed by the Mantel test. ${ }^{7}$ In order to account sim- \& ultaneously for the reciprocal potential con- $\vec{O}$ founding effect of several factors, we used unconditional multiple logistic regression with $\vec{\omega}$ maximum likelihood fitting. ${ }^{8}$ Included in the regression equations were terms for age, parity, plus factors found in the age adjusted analysis $\dot{v}$ to be significantly (at the usual level of $\mathrm{p}<0.05$ ) associated with ovarian cysts.

\section{Results}

Table 1 shows the distribution of cases and controls according to age and selected characteristics. The risk of seromucinous benign ovarian cysts was higher in more educated women: in comparison with women reporting less than seven years of schooling, the OR of seromucinous ovarian cysts were 1.3 and 1.4 respectively in women reporting $7-11$ and $\geq 12$ years of schooling $\left(\chi^{2}{ }_{1} 5.20, \mathrm{p}=0.02\right)$. The corresponding multivariate estimates including terms for age, parity, education, lifelong menstrual pattern, and difficulties in conception were $1.3(95 \%$ CI $0.9,2.1)$ and $1.7(95 \%$ CI 1.0, 2.8; multivariate $\chi_{1}{ }_{1}$ trend $4.41, \mathrm{p}=0.03$ ).

No relationship emerged between risk of seromucinous ovarian cysts and marital status, oral contraceptive use, body mass index, and age at first marriage. The OR of ovarian cysts for ever OC users, in comparison with never users, was $1.5(95 \% \mathrm{CI} 0.8,2.9)$, but no clear relationship emerged with duration of OC use. Likewise, smoking was not associated with seromucinous cysts: in comparison with never smokers the OR were 0.6 (95\% CI $0.4,1.1)$ o and $1.1(95 \%$ CI $0.8,1.7)$ respectively for women smoking $<10$ and $\geq 10$ cigarettes per day. Ex-smokers tended to be at somewhat lower risk, but the finding was of borderline statistical significance (OR $0.5,95 \% \mathrm{CI}, 0.3$, $\left.1.0 ; \chi_{1}^{2} 3.74 ; \mathrm{p}=0.05\right)$.

Menstrual and reproductive factors are considered in table 2 . In comparison with women reporting menstrual cycles lasting $<28$ days, the OR of seromucinous cysts were $1.6(95 \%$ CI $0.9,2.7), 2.6$ (95\% CI 1.2, 5.8), and 2.5 $(95 \%$ CI $1.1,5.6)$ respectively in women reporting cycles lasting $28-30$ and $\geq 31$ days, and in those with totally irregular cycles. The corresponding multivariate estimates were 1.6 .

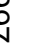
, . .

\section{.} .

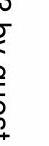


(95\% CI 0.9, 2.8), 2.3 (95\% CI 1.1, 5.3), and $2.4(95 \%$ CI $1.1,5.2)$. No relation emerged between age at menarche, age at the menopause and the risk of seromucinous cysts. Likewise, parity, history of spontaneous or induced abortion, and age at first and last birth were not associated with seromucinous cysts.

Among ever married women, nine cases $(5.8 \%)$ and two controls $(0.7 \%)$ reported difficulty in conception: the corresponding crude OR of seromucinous cysts was 8.8 (95\% CI $2.1,37.0)$ and the age adjusted OR was 17.7 (95\% CI 4.2, 83.8).

\section{Discussion}

The results show that the risk of seromucinous benign ovarian neoplasms is higher in more educated women, in women with a history of infertility, and in those with long/irregular menstrual cycles. These findings are in partial agreement with the scanty published data on the epidemiological characteristics of women with ovarian adenomas. A case-control study conducted on about 60 cases with benign epithelial neoplasm showed an increased risk of ovarian adenomas in nulliparae and in women who had investigations for infertility. ${ }^{4}$ Similar findings emerged from the Oxford Family Planning Association study. ${ }^{2}$ In that study, the rate of cystoadenomas was about $40-50 \%$ lower in parae than in nulliparae. In the present study, however, whereas the association with infertility was confirmed, there was no clear pattern of trend with parity. The lack of association between parity and risk of seromucinous cysts in the study may be explained by the low percentage of parous women in controls (43\% of controls were nulliparae). However, the frequency of nulliparae was consistent with data from other epidemiological studies conducted in the same population of comparable strata of age. ${ }^{9}$ Irregular menstrual cycles, which were related with the risk of seromucinous cysts in the present study, may also be an indirect indicator of infertility.

Previous studies have suggested that the risk of the disease tended to be low in women reporting late age at menarche. ${ }^{4}$ For instance, a case-control study conducted in London showed an OR of benign epithelial neoplasm of 0.4 in women reporting menarche at age 12 or later in comparison with those reporting menarche before 12 years of age. ${ }^{4}$ Later age at menarche has been suggested to have a protective role on the risk of ovarian cancer, too. ${ }^{10} \mathrm{We}$ did not find any relationship between age at menarche and the risk of seromucinous cysts. Some of these differences may still be interpreted in terms of the different criteria for definition and inclusion of cases in the two studies. For example, late menarche has been suggested to be protective towards benign endometrioid ovarian cysts. ${ }^{11}$

Our study found no significant association between OC use and risk of ovarian cysts. This lack of association was reproduced in strata of duration of use. Although our results are based on limited numbers of OC users, they agree with most previous results. ${ }^{24}$ No association between cystadenoma and OC use emerged, for example, in an English case-control study, ${ }^{4}$ and in the Oxford Family Planning Association cohort study. ${ }^{2}$

Potential limitations of this study should be discussed. First, a point of concern is the low statistical power, particularly for factors with a low prevalence of exposure in the population, such as OC use. Also for factors found significantly associated with the risk of seromucinous benign ovarian cyst in the analysis, such as difficulties in conception, the small number of cases and controls reporting the factor does not provide the opportunity of adequately taking into account potential confounding. Concerning possible information bias, interviewers were not blind to the casecontrol status, but they were not aware of the specific end points of this analysis. Furthermore, hospital controls are likely to provide information more similar to that of cases than population controls in several aspects, and particularly concerning menstrual and obstetric history and drugs use. Overall, it is unlikely that information bias is a major problem in the definition of reproductive and menstrual characteristics or of general lifestyle or socioeconomic indicators, particularly in younger women. Selection should not be a major problem either: cases and controls were identified in institutions covering similar catchment areas and participation was almost complete.

Higher education was associated with an increased risk of seromucinous ovarian cysts. A direct association between socioeconomic indicators and the risk of benign gynecological conditions is a common finding in epidemiological studies. For example, studies conducted in the same geographic areas and with similar design have shown a higher risk of uterine fibroids, ${ }^{12}$ pelvic and ovarian endometriosis, ${ }^{13}$ and benign breast disease ${ }^{14}$ in more educated women. Any interpretation of these findings remains uncertain, but diagnostic and selection biases probably have some role. Although overcoming this potential bias completely is difficult, allowance for education, as well as other potential distorting factors, did not materially modify any of the estimated relative risks for infertility and menstrual history.

In conclusion, this study offers information on the epidemiological characteristics of benign ovarian cysts. Its results can be considered in comparison with the epidemiology of ovarian cancer. In particular, the observation that infertility increases the risk of seromucinous ovarian cysts agrees with findings for ovarian cancer. ${ }^{10}$ However, a few discrepancies emerged, particularly the lack of a clear protective role of parity and OC, two well recognised protective factors for ovarian cancer, and suggest that some of the exposures which define the incidence of benign and malignant ovarian lesions may differ.

Funding: this work was conducted within the framework of the CNR (Italian National Research Council) applied projects 95.0056 Applications of Oncological Research (contract no 
(contract no 95.00952.PF41) and with grants in aid from the Italian Ministry of Health and the Europe Against Cancer Programme of the Commission of the European Communities. Conflicts of interest: none. The contributions of the Italian Association for Cancer Research
and Italian League Against Tumours, Milan, Italy, are gratefully and Italian League Against Tumours, Milan, Italy, are gratefully acknowledged. Ms Ivana Garimoldi, Ms Judy Baggott and the GA Pfeiffer Memorial Library Staff provided editorial assistance.
We wish to thank Dr Carmela Mezzanotte for her help in preparation of the manuscript.

1 Westhoff C, Clark CJG. Benign ovarians cysts in England and Wales and in the United States. Br f Obstet Gynaecol 1992;99:329-32.

Vessey M, Metcalfe A, Wells C, McPherson K, Westhoff C, Yeates D. Ovarian neoplasms, functional ovarian cysts, and oral contraceptives. BMF 1987;294:1518-20.

3 Parazzini F, La Vecchia C, Franceschi S, Negri E, Cecchetti G. Risk factors for endometrioid, mucinous and serous benign ovarian cysts. Int $\mathcal{F}$ Epidemiol 1989;18:108-12.

4 Booth M, Beral V, Maconochie N, Carpenter L, Scott C. A case-control study of benign ovarian tumours. $\mathcal{F}$ Epidemiol Community Health 1992;46:528-31.

5 Parazzini F, La Vecchia C, Negri E, Bocciolone L, Fedele $\mathrm{L}$, Franceschi S. Oral contraceptive use and the risk of ovarian cancer: an Italian case-control study. Eur $\mathcal{F}$ Cancer 1991;28:594-8.
6 Mantel N, Haenszel WS. Statistical aspects of the analysis of data from retrospective studies of disease. 7 Natl Cancer Inst 1959;22:719-48.

7 Mantel N. Chi-square tests for one degree of freedom; extensions of the Mantel-Haenszel procedure. $\mathcal{F} \mathrm{Am} \mathrm{Stat}$ Assoc 1963;58:690-700.

8 Baker RJ, Nelder JA. The GLIM system, release 3. Numerica Algorithms Group, Oxford, 1978.

9 Parazzini F, Ferraroni M, Tozzi L, Ricci E, Mezzopane R, La Vecchia C. Induced abortions and risk of ectopic pregnancy. Hum Reprod 1995;10:1841-4.

10 Parazzini F, Franceschi S, La Vecchia C, Fasoli M. The epidemiology of ovarian cancer. Gynecol Oncol 1991;43. 9-23.

11 Cramer DW, Wilson E, Stillman RJ, et al. The relation of endometriosis to menstrual characteristics, smoking, and exercise. $¥ A M A$ 1986;255:1904-8.

12 Parazini F, La Vecchia C, Negri E, Cecchetti G, Fedele L. Epidemiologic characteristics of women with uterine fibroids: a case-control study. Obstet Gynaecol 1988;72: 853-7.

13 Parazzini F, Ferraroni M, Fedele L, Bocciolone L, Rubess $S$, Riccardi A. Pelvic endometriosis: reproductive and menstrual risk factors at different stages in Lombardy, northern Italy. F Epidemiol Community Health 1995;49: 61-4.

14 Parazzini F, La Vecchia C, Franceschi S, et al. Risk factors for pathologically confirmed benign breast disease. $\mathrm{Am}$ Epidemiol 1984;120:115-22. 